\title{
Influence of Color on Attractiveness of Petit Facial Mask
}

\author{
${ }^{1}$ Matheus Melo Pithon, ${ }^{2}$ Matheus Souza Campos Costa, ${ }^{3}$ Raildo Coqueiro, ${ }^{4}$ Felipe Couto, ${ }^{5}$ Rajiv Saini
}

\section{ABSTRACT}

Aims: Evaluate the esthetic attractiveness of the Petit type facial masks of different colors among youngsters from public and private schools.

Materials and methods: Eight orthopedic facial masks of the Petit type, in different colors were evaluated. Images were obtained of the same patient, and were standardized with a program for changing images (Adobe Photoshop software from CS). The following colors were inserted in the masks: white, gray, green, yellow, blue, pink, orange and black. After acquisition, the images were printed on photographic paper and incorporated into a specific and personalized questionnaire. The questionnaire was distributed among children of both genders, in the age ranges from 7 to 8 , and 9 to 10 years, at public and private schools $(n=200)$. For the scores attributed to each image, the Mann-Whitney test was used, and among groups, Spearman's correlation. The level of significance adopted was $5 \%$.

Results: Only the scores attributed to the color brown presented significant difference between the schoolchildren from public and private schools. In a comparison between genders, the boys awarded better scores to the colors gray, blue and black, whereas the girls awarded better scores to the color pink. When comparing the age ranges examined there were no statistical differences.

Conclusion: The color of the Petit type of facial mask has an influence on the esthetic attractiveness to children from 7 to 10 years, and preference for certain colors is also influenced by gender and the type of school (public or private).

Keywords: Orthopedic appliances, Angle's class III malocclusion, Esthetics.

How to cite this article: Pithon MM, Costa MSC, Coqueiro R, Couto F, Saini R. Influence of Color on Attractiveness of Petit Facial Mask. Int J Experiment Dent Sci 2015;4(2):99-103.

Source of support: Nil

Conflict of interest: None

\footnotetext{
${ }^{1,3}$ Professor, ${ }^{2,4}$ Student, ${ }^{5}$ Associate Professor

${ }^{1-4}$ Department of Orthodontics, Southwest Bahia State University, Bahia, Brazil

${ }^{5}$ Department of Periodontology, Pravara Institute of Medical Sciences, Ahmednagar, Maharashtra, India

Corresponding Author: Matheus Melo Pithon, Professor Department of Orthodontics, Southwest Bahia State University Bahia, Brazil, Phone: 557730842020, e-mail: matheuspithon@ gmail.com
}

\section{INTRODUCTION}

Class III malocclusion may be the result of a bone or dental decompensation. The majority of cases are linked to maxillomandibular bone discrepancies, which may be caused by maxillary deficiency, either associated with mandibular protrusion, or not. ${ }^{1,2}$ Dental discrepancies may frequently be resolve by orthodontic treatment. Whereas, for cases of bone disharmony, there are various treatment philosophies and it behooves the orthodontist to choose the type of treatment and the right time for intervention. There are three main types of approaches described in the literature, which depend on the patient's age; rapid maxillary expansion combined with facial mask therapy, which must begin on conclusion of primary dentition or at the beginning of mixed dentition; ${ }^{3-5}$ bone anchorage by means of intermaxillary elastics for class III, which must begin on conclusion of mixed dentition or at the beginning of permanent dentition; and orthognathic surgery which should be performed when the individual has stopped growing. 6,7

Therapy with a facial mask provides a constant anterior force on the maxilla, which changes the orientation of facial growth and is indicated particularly for cases of class III malocclusion, due to the anteroposterior and transverse deficiency of the maxilla ${ }^{8,9}$ Among the various types of facial masks available, there is the Petit type of mask, which is a prefabricated mask, easily found on the market, and allows the line of force to be adjusted by altering the external support elastics. It consists of one point of support in front and other on the chin and applies traction to the maxilla in the direction of its growth, forward and downward. It has the disadvantage of causing strabismus and the effect of rotating the mandible in the clockwise direction. 8,10

One of the great limitations of this therapy is the lack of commitment and cooperation by the patient and parents with regard to use of the appliance for the period determined by the orthodontist or pediatric dentist. It is worth pointing out that high value is placed on esthetics nowadays, and in many cases the use of the appliance coincides with the prepuberal period, in which the patient's body is on the point of beginning the process of accelerated growth, changes in body composition and sexual maturation, which may be accompanied by psychological changes. Therefore, many patients find it very difficult to accept treatment with external appliances, 
and this frequently leads to being unfavorable to the effectiveness of treatment. By virtue of the problem described, a fair question arise, would the color of the masks be a factor that would lead to greater or less commitment to treatment by these patients?

Based on the foregoing discourse, the aim of this study was to evaluate the esthetic attractiveness of the Petit type of facial mask in different colors. The preferences of youngsters from public and private schools, of both genders, in the age range from 7 to 10 years were evaluated.

\section{MATERIALS AND METHODS}

The study was conducted with digitized images of a patient wearing a Petit type of orthopedic facial mask, with the aim of evaluating the esthetic preferences of children from public and private schools, of both genders, in the age range from 7 to 10 years old. A specific personalized questionnaire was produced, which allowed precise and reproducible responses about the esthetic appearance of the orthopedic face masks. The images were captured with a digital camera (Canon Rebel XTI, macro $60 \mathrm{~mm}$, Japan) mounted on a tripod with a fixed focus/object distance.

The images were uploaded onto a computer and standardized with the aid of image manipulation software (Adobe Photoshop CS, Adobe Systems Inc, San Francisco, CA). To limit the confounding variables, the same model was used, with the same shirt and image background. The masks were standardized in the colors white, gray, green, yellow, blue, pink, orange and black (Fig. 1). After acquisition, the images were printed on photographic paper and incorporated into the questionnaire. For participation in the research, children in the age range from 7 to 10 years of age, who had never been submitted to treatment with an orthopedic face mask were selected. All of the surveys were made during consultations held in the pediatric dentistry courses of the School of Dentistry, of the State University of Southwestern Bahia. The questionnaires were handed out, and the participants were asked not to proceed with the next question, if they had not answered the previous one. The subjects were informed that these images represented their capacity to select various face masks for orthodontic
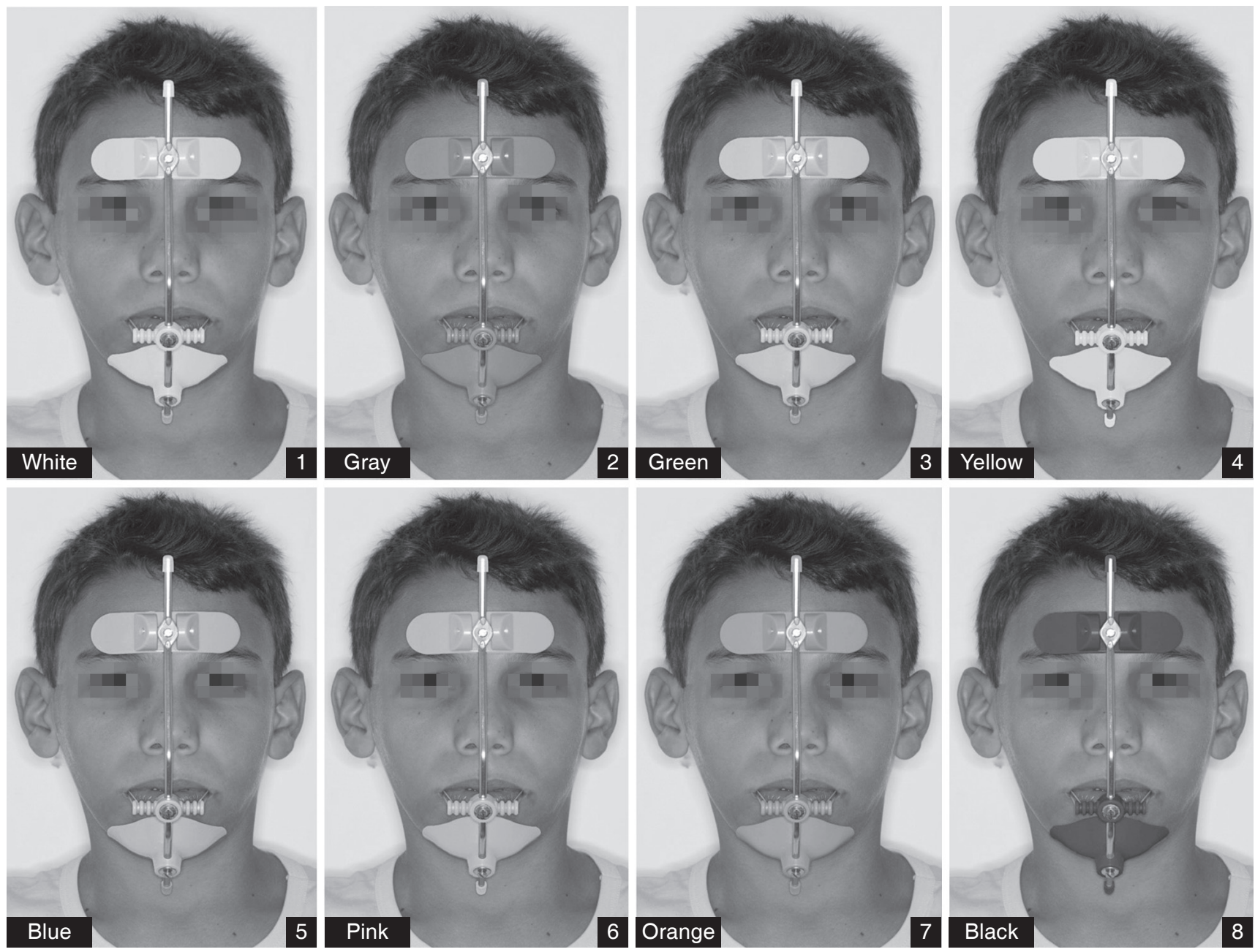

Fig. 1: Petit facial mask of maxillary protractor inserted in a patient shown in different colors: 1—White; 2-gray; 3-green; 4-yellow; 5-blue; 6-pink; 7-orange; 8-black 
Influence of Color on Attractiveness of Petit Facial Mask

treatment. They were instructed to take 1 minute to look as all the images before beginning the research. By doing this, the subjects were able to familiarize themselves with all the masks before evaluating the image exhibited for the first time. After this, the images were presented with a printed scale showing values that ranged from 0 to 10 , in which they attributed a score to the image, with 10 being the best and 0 the worst image.

To arrive at the number of individuals to be researched, a sample calculation was made, and the number of 200 individuals was found for the target population studied. Each research image was evaluated twice for reliability. All the values used for statistical analysis were means of both evaluations. For acceptability, recorded as zero or one, this produced a value of 0.5 if the subject evaluated chose the mask as acceptable at one moment and unacceptable at another. These responses represented an acceptable lie of analysis of the face masks.

The research was conducted in compliance with the criteria established by Resolution CNS 196/96 of the Ministry of Health (Brazil, 1996). Thus, the form was only applied after it was approved by the Research Ethics Committee of the Southwest Bahia State University, Protocol Number 175/2011-CAAE 0154.0.454.000-11.

The scores of the grades attributed to each image were compared using the Mann-Whitney U test. The means of scores awarded to each image were calculated in each group in order to determine the Spearman correlation coefficients, to evaluate the similarity between the schoolchildren's perceptions by type of school, gender and age group. The level of significance adopted was 5\% $(\alpha=0.05)$. The data were tabulated and analyzed in the statistical program BioEstat (version 5.0, Belém-PA, Brazil).

\section{RESULTS}

Table 1 shows the demographic data of the study participants. The mean \pm standard deviation (SD) of participants' age was $8.9 \pm 1.1$ years.

Table 1: Demographic data of study participants per groups

\begin{tabular}{lll}
\hline Characteristics & $\begin{array}{l}\text { Public school } \\
(n=100)\end{array}$ & $\begin{array}{l}\text { Private school } \\
(n=100)\end{array}$ \\
\hline Age (years) & & $8.5 \pm 1.1$ \\
Mean \pm SD & $9.2 \pm 0.9$ & 8.0 \\
Median & 10.0 & $7.0-10.0$ \\
Max-mín & $7.0-10.0$ & \\
Gender & & $50(50.0 \%)$ \\
Male & $50(50.0 \%)$ & $50(50.0 \%)$ \\
Female & $50(50.0 \%)$ & \\
Age range & & $52(52.0 \%)$ \\
7 to 8 years & $24(24.0 \%)$ & $48(48.0 \%)$ \\
9 to 10 years & $76(76.0 \%)$ & \\
\hline
\end{tabular}

Table 2: Mean scores (standard deviation) attributed to the masks, divided by type of school

\begin{tabular}{|c|c|c|c|}
\hline \multirow[b]{2}{*}{ Image } & \multicolumn{2}{|c|}{ Type of school } & \multirow[b]{2}{*}{$p$-value } \\
\hline & Public school & Private school & \\
\hline White & $5.10(3.81)$ & $4.84(3.52)$ & 0.769 \\
\hline Gray & $5.23(3.24)$ & $4.84(2.76)$ & 0.458 \\
\hline Green & $5.90(2.84)$ & $5.65(2.25)$ & 0.455 \\
\hline Yellow & $6.61(2.57)$ & $6.14(2.59)$ & 0.269 \\
\hline Blue & $6.83(2.73)$ & $6.31(2.81)$ & 0.209 \\
\hline Pink & $7.08(2.78)$ & $6.58(3.02)$ & 0.299 \\
\hline Orange & $7.14(2.74)$ & $6.15(3.12)$ & 0.038 \\
\hline Black & $6.60(3.47)$ & $6.70(3.29)$ & 0.874 \\
\hline
\end{tabular}

Table 3: Mean scores (standard deviation) attributed to the photograph by the children, divided by gender

\begin{tabular}{llll}
\hline & \multicolumn{3}{c}{ Gender } \\
\cline { 2 - 3 } & Male & \multicolumn{2}{c}{ Female } \\
\hline White & $5.29(3.67)$ & $4.65(3.63)$ & 0.195 \\
Gray & $5.74(3.03)$ & $4.33(2.83)$ & 0.001 \\
Green & $5.95(2.79)$ & $5.59(2.43)$ & 0.333 \\
Yellow & $6.39(2.55)$ & $6.35(2.63)$ & 0.933 \\
Blue & $6.92(2.87)$ & $6.21(2.63)$ & 0.030 \\
Pink & $6.32(2.96)$ & $7.34(2.77)$ & 0.005 \\
Orange & $6.45(2.96)$ & $6.84(2.99)$ & 0.316 \\
Black & $7.32(3.3)$ & $5.99(3.49)$ & 0.002 \\
\hline
\end{tabular}

Table 4: Mean scores (standard deviation) attributed to the photograph by the children, divided by age ranger

\begin{tabular}{llll}
\hline & \multicolumn{3}{c}{ Age range } \\
\cline { 2 - 3 } & 7 to 8 years & 9 to 10 years & \\
\hline White & $4.49(3.78)$ & $5.02(3.60)$ & 0.671 \\
Gray & $4.71(3.05)$ & $5.23(2.98)$ & 0.246 \\
Green & $5.68(2.54)$ & $5.83(2.58)$ & 0.575 \\
Yellow & $6.70(2.56)$ & $6.17(2.50)$ & 0.227 \\
Blue & $6.53(2.77)$ & $6.59(2.79)$ & 0.915 \\
Pink & $6.79(2.92)$ & $6.85(2.91)$ & 0.902 \\
Orange & $6.17(2.91)$ & $6.63(3.03)$ & 0.930 \\
Black & $6.65(3.35)$ & $6.65(3.40)$ & 0.921 \\
\hline
\end{tabular}

The mean of scores attributed to each image, per type of school is shown in Table 2. Only the scores attributed to the color brown showed significant difference between the schoolchildren from public and private schools.

Significant differences were found between the colors gray, blue, pink and black, when the mean scores attributed were divided according to gender, as is shown in Table 3. Comparisons between pair showed that boys attributed better scores to all the colors except pink, to which the girls attributed better scores.

There were no statistical differences between the scores attributed in comparison with the age range examined, as described in Table 4.

\section{DISCUSSION}

In the literature, the most accepted early treatment of class III malocclusion, resulting from maxillary atresia, 
is that which uses palatine separation followed by protraction with a facial mask. This therapy is capable of promoting transverse expansion and anterior protraction of the maxilla. However, it is a treatment that depends on the professional's experience and knowledge and is directly related to the degree of cooperation by the patient and his/her family members. There are various types of facial masks described in the literature, which may be prefabricated or custom made. Basically, they all have the same purpose: To cause maxillary protraction and redirect mandibular growth. Each of these has characteristics and advantages that must be administered by the orthodontist at the time these masks are chosen. $3,5,8,11$

The first facial masks used for maxillary protraction were created by Potpeschnigg in 1875. After this, Delaire et al $(1976)^{12}$ developed an appliance to promote maxillary protraction and correct posterior rotation of the maxilla, and developmental deficiency. Later Petit ${ }^{13}$ modified Delaire's basic concept, changing the form of the wire structure that unites the connection surfaces, increasing the dynamism and magnitude of force generated by the appliance, thus reducing the total length of treatment time. ${ }^{14-17}$

The Petit mask is characterized by having one support in front and a satisfactory one on the chin, capable of supporting the heavy forces necessary for maxillary protraction. The reaction in front appears to produce a small effect of cranial deformation, while the reaction on the chin is efficient in the control of excessive mandibular growth, or of its compensation in relation to the temporomandibular joint. This is a prefabricated mask that allows the line of action to be adjusted, and is capable of applying traction to the maxilla in the direction of its growth forward and downward. It has the disadvantage of cause a rotational effect on the mandible in the clockwise direction, and is not indicated for a long-faced patient. ${ }^{10,12,13}$

In this contex, class III malocclusion not only affects occlusion and masticatory function. Dentofacial appearance and harmony generally lead to psychological problems in children, such as negative and self-deprecating attitudes and low self-esteem. It is precisely at this stage - the prepuberal period—-that the Orthodontist and Pediatric Dentist should intervene, seeking to control the psychological problems and correct the malocclusion. ${ }^{18,19}$ The use of facial masks, in this case, is inevitable and they frequently need to be used for 12 to 16 hours per day and for periods of various lengths. Therefore, analyzing the acceptance and esthetic attractiveness of the Petit type of mask in different colors offers support to professionals to know how children see them, and whether colors contribute to making them more attractive. Thus, in the present article, the author's goal was to evaluate the attractiveness of the Petit type of facial masks in eight different colors.
The opinion of children from 7 to 10 years was used, as they are in the age range in which orthopedic treatment with these types of facial masks should be started. The groups examined were divided according to age range from 7 to 8 years and 9 to 10 years; gender and types of school—public and private (Table 1). An endeavor was made to analyze whether the socioeconomic characteristics of the participants had any influence on the attractiveness of the masks.

For this purpose, the children were asked to attribute a score (0 to 10) to the colors of the face masks. It was observed that only the color brown presented statistical differences between the types of schools, showing that the school children considered the brown color to be more attractive (Table 2). However, as the other colors presented no statistical significance, it could be inferred that the colors of the masks were not greatly influenced by the socioeconomic characteristics of the participants.

Whereas in an approach according to gender, it was observed that the scores attributed to the colors gray, blue, pink and black presented statistical differences when compared between the genders (Table 3). The boys preferred the colors gray, blue and black and attributed better scores to these, while the girls attributed better scores to the color pink. Thus, it was found that the colors conventionally linked to gender: pink for girls and blue or black for boys are cultural markers that guide the preferences in children. ${ }^{20}$ When one works with orthodontic appliances, one can observe an increase in attractiveness of appliances when the patient has the possibility of choosing the color. It has been observed that children and adolescents prefer appliances that use colored elastomeric ties, in comparison with self-ligating appliances that do not use the system of connection by elastics. ${ }^{21}$

This possibility of the choice of color may also have been influenced by the age range examined, considering that children and adolescents present differences in the choice of colors of orthodontic appliances. Older children prefer lighter colors in comparison with younger ones. ${ }^{20,21}$

In this study, a computer was used to alter the colors of the face masks, which may be a criticism of this study, since in clinical practice one is unable to faithfully achieve the colors here presented. Nevertheless, as the same image was used, and only the variable (color) was changed, it cannot be considered a methodological problem. Moreover, the major purpose of this study was not to set up a database to inform the most attractive colors, but to demonstrate that colors have an influence on the choice and acceptance of the mask, therefore, a discussion between the patient and professional about the subject is be necessary. 
The use of means to represent the groups examined is difficult to apply to a patient in the dental chair. Thus, the information should be interpreted carefully, and apply it with caution, in order to personalize this method of evaluation, and allowing each patient to choose, as far as possible, the color of the mask to be used.

\section{CONCLUSION}

The color of the Petit type of facial mask has an influence on the esthetic attractiveness to children from 7 to 10 years, and preference for certain colors is also influenced by gender and the type of school (public or private).

\section{REFERENCES}

1. Lacour M. Contraindications to the use of extraoral forces in dentofacial orthopedics. Rev Stomatol Chir Maxillofac 1976; 77(2):563-567.

2. Kucukkeles N, Nevzatoglu S, Koldas T. Rapid maxillary expansion compared to surgery for assistance in maxillary face mask protraction. Angle Orthod 2011;81(3):42-49.

3. Westwood PV, McNamara JA Jr, Baccetti T, Franchi L, Sarver DM. Long-term effects of class III treatment with rapid maxillary expansion and facemask therapy followed by fixed appliances. Am J Orthod Dentofac Orthop 2003;123(1): 306-320.

4. Ngan PW, Hagg U, Yiu C, Wei SH. Treatment response and long-term dentofacial adaptations to maxillary expansion and protraction. Semin Orthod 1997;3(5):255-264.

5. Baik HS. Clinical results of the maxillary protraction in Korean children. Am J Orthod Dentofac Orthop 1995;108(1): 583-592.

6. Parton AL, Tong DC, De Silva HL, Farella M, De Silva RK. A 9 years review of orthognathic surgery at the University of Otago. N Z Dent J 2011;107(3):117-120.

7. Proffit WR, Turvey TA, Phillips C. Orthognathic surgery: a hierarchy of stability. Int J Adult Orthodon Orthognath Surg 1996;11(2):191-204.

8. Macdonald KE, Kapust AJ, Turley PK. Cephalometric changes after the correction of class III malocclusion with maxillary expansion/facemask therapy. Am J Orthod Dentofac Orthop 1999;116(4):13-24.
9. Kim JH, Viana MA, Graber TM, Omerza FF, BeGole EA. The effectiveness of protraction face mask therapy: a meta-analysis. Am J Orthod Dentofac Orthop 1999;115(5): 675-685.

10. Gallagher RW, Miranda F, Buschang PH. Maxillary protraction: treatment and post-treatment effects. Am J Orthod Dentofac Orthop 1998;113(6):612-619.

11. Baccetti T, Rey D, Angel D, Oberti G, McNamara JA Jr. Mandibular cervical headgear vs rapid maxillary expander and facemask for orthopedic treatment of class III malocclusion. Angle Orthod 2007;77(2):619-624.

12. Delaire J. Mandibular prognathic syndrome. Orthod Fr 1976; 47(1):203-219.

13. Petit $\mathrm{H}$. Introduction to the biomechanical study of the facial mask and its accessories. Orthod Fr 1983;54(4):353-365.

14. Philippe J, Guedon P. Evolution of orthodontic appliances from 1728 to 2007. Inaugural Conference of the 79th Scientific Meeting of the SFODF at Versailles, 31 May 2007. Orthod Fr 2007;78(5):295-302.

15. Gysel C. Origine and evolution of extraoral therapy. Rev Belge Med Dent 1974;29(5):251-264.

16. Turley PK. Orthopedic correction of class III malocclusion with palatal expansion and custom protraction headgear. J Clin Orthod 1988;22(1):314-325.

17. McNamara JA Jr. An orthopedic approach to the treatment of class III malocclusion in young patients. J Clin Orthod 1987; 21(3):598-608.

18. Stricker G, Clifford E, Cohen LK, Giddon DB, Meskin LH, Evans CA. Psychosocial aspects of craniofacial disfigurement. A 'State of the Art' assessment conducted by the Craniofacial Anomalies Program Branch, The National Institute of Dental Research. Am J Orthod 1979;76(2):410-422.

19. Flanary CM, Barnwell GM, VanSickels JE, Littlefield JH, Rugh AL. Impact of orthognathic surgery on normal and abnormal personality dimensions: a 2-year follow-up study of 61 patients. Am J Orthod Dentofac Orthop 1990;98(4): 313-322.

20. Elekdag-Turk S, Ozkalayci N, Isci D, Turk T. Color preferences of patients receiving elastic ligatures. Eur J Dent 2010;4(5): 171-174.

21. Walton DK, Fields HW, Johnston WM, Rosenstiel SF, Firestone AR, Christensen JC. Orthodontic appliance preferences of children and adolescents. Am J Orthod Dentofac Orthop 2010;138(5):698-699. 